\title{
Percepção de Alunos Superdotados, Mães e Professores Acerca da Aceleração de Ensino
}

\author{
Renata Rodrigues Maia-Pinto* \\ Denise de Souza Fleith \\ Universidade de Brasília, Brasília, DF, Brasil
}

\begin{abstract}
RESUMO
O objetivo deste estudo exploratório foi investigar a percepção de alunos superdotados, do ensino fundamental, submetidos a procedimentos de aceleração de ensino quando frequentavam a educação infantil, suas mães e professores acerca dessa prática. Foram entrevistados 12 estudantes, 12 mães, 10 professores de salas de aula regular e cinco docentes que atuavam em um programa de atendimento a alunos superdotados. Os resultados indicaram que a aceleração foi uma intervenção bem-sucedida para os alunos, não acarretando perdas acadêmicas ou dificuldades socioemocionais nas séries seguintes. Mães e alunos avaliaram positivamente a experiência de aceleração de ensino, ao passo que os professores se posicionaram desfavoravelmente, embora não tenham identificado problemas emocionais ou de desempenho escolar em seus alunos acelerados.
\end{abstract}

Palavras-chave: superdotação; aceleração de ensino; aluno superdotado.

\begin{abstract}
Gifted Students, Mothers, and Teachers' Perceptions about Acceleration

The purpose of this exploratory study was to investigate the perception of elementary school gifted students, who went through the process of acceleration when attending early childhood education, their mothers and teachers about this practice. Twelve students, 12 mothers, 10 teachers from regular classrooms and five teachers from a program for gifted students were interviewed. The results indicated that academic acceleration was a successful intervention for students, not resulting in academic losses or socio-emotional difficulties in the following grades. Mothers and students have evaluated acceleration positively while teachers positioned themselves unfavorably in relation to acceleration, although they have not identified emotional or academic problems in their accelerated students.
\end{abstract}

Keywords: giftedness; academic acceleration; gifted student.

Estudiosos da área de superdotação têm expressado preocupação com o desperdício de talentos em vários países, resultado de limitadas estratégias de identificação e políticas de atendimento às necessidades de alunos com altas habilidades, bem como da escassez de práticas educacionais pouco desafiadoras e inovadoras (Alencar \& Fleith, 2006; Colangelo \& Assouline, 2005; Lee \& Olszewski-Kubilius, 2006; Merry, 2008; Renzulli, 2001; Shavinina, 2009). A inserção de superdotados em um ambiente estimulador, onde possam desenvolver suas habilidades e encontrar pares que compartilhem seus interesses e apresentem ritmo de aprendizagem semelhante, pode contribuir para o seu bem-estar e sua satisfação em aprender. Por outro lado, quando as necessidades desses alunos não são atendidas, frequentemente, são observados descontentamento com a escola, sub-rendimento acadêmico, tédio, sintomas de depressão e sofrimento por bullying (Colangelo, Assouline, \& Gross, 2004; Lubinski, 2004).

Neste sentido, a aceleração de ensino tem sido apontada como uma estratégia alternativa de atendimento educacional ao superdotado, pois, ele pode mover-se pelo currículo, no seu ritmo, em áreas que

* Endereço para correspondência: Renata Rodrigues Maia-Pinto - renata.6178@gmail.com 
domina. A estratégia tem, ainda, o objetivo de encurtar o tempo de permanência do estudante em um ambiente de educação seriada, propiciando o seu avanço acadêmico em um ou mais momentos de sua vida (Alencar \& Fleith, 2001; Colangelo et al., 2004; Rogers, 2004, 2007). Existem diversas modalidades de aceleração (Maia-Pinto \& Fleith, 2012; Rogers, 2004): o aluno pode avançar em uma ou mais disciplinas para séries em que se encaixar melhor, "pular" uma determinada série escolar, ser admitido precocemente na escola ou universidade e pode, ainda, completar dois ou mais anos de estudo em um ano. Tem, também, a opção de fazer cursos por correspondência ou cursar disciplinas na universidade, como aluno especial, cujos créditos poderão ser aproveitados quando do seu ingresso regular na instituição de ensino superior.

Estudos internacionais confirmam a eficácia da aceleração para o superdotado (Colangelo et al. 2004; Hoogeveen, Hell, \& Verhoeven, 2009; Kleinbok \& Vidergor, 2009; Lee, Olszewski-Kubilius, \& Peternel, 2010; Ma, 2003; Merry, 2008; Oliveira, 2007; Rogers, 2004, 2007; Schiever \& Maker, 1997; Steenbergen$\mathrm{Hu} \&$ Moon, 2011). Essa prática promove melhor desempenho acadêmico, elevada motivação para aprender, maior envolvimento com as atividades escolares e autoconceito positivo. Ma (2003) defende que o aluno acelerado poderá satisfazer seus interesses acadêmicos e construir bases sólidas para aprendizados futuros. Esse é um argumento que merece atenção, principalmente quando se considera a criança em idade pré-escolar, já que nessa faixa etária o aluno superdotado costuma apresentar vocabulário avançado para a idade, habilidades de leitura e escrita precoces, ritmo de aprendizagem rápido, pensamento abstrato e analítico e boa memória (Alencar \& Fleith, 2001). Rogers (2004) examinou dezenas de estudos que avaliaram a entrada precoce de crianças na pré-escola. Segundo a pesquisadora, os benefícios são inúmeros, uma vez que, para as crianças superdotadas, a evolução das atividades do currículo regular parece lenta, e isso pode levá-las a perder o interesse pela escola. Ao contrário, quando as atividades curriculares são desenvolvidas de forma mais acelerada, de acordo com o ritmo de aprendizagem da criança, sua motivação e participação aumentam.

Contudo, não é incomum educadores e familiares expressarem resistência com relação à implantação da aceleração, especialmente no que diz respeito à entra- da precoce no $1^{\circ}$ ano do ensino fundamental e ao avanço de série. Segundo Colangelo e Assouline (2005) e Howley (2002), entre os motivos para tal postura, podem ser mencionados: pouca familiaridade com as pesquisas sobre aceleração; filosofias pessoais segundo as quais a criança será mantida distante de seus pares em idade; crença de que a aceleração suprime parte da infância da criança; medo de que a aceleração a prejudique social e emocionalmente; entendimento político sobre a oferta de oportunidades iguais para os alunos; e argumento de que os alunos deixarão de aprender parte do conteúdo programático. Segundo Diezmann, Watters e Fox (2001), existem dificuldades em estabelecer vantagens e desvantagens em torno da aceleração, porque as informações veiculadas a respeito dessa prática misturam fatos e ficção. São necessárias discussões mais aprofundadas no que se refere, especialmente, a concepções de profissionais da educação e de familiares quanto ao uso da aceleração de ensino.

No Brasil, a prática de aceleração, segundo Delou (2001), é mais comum nas séries iniciais, sempre que os alunos demonstram competências escolares acima daquelas apresentadas por seus pares da mesma série/idade. Entretanto, na opinião da autora, não há preparo dos professores nem acompanhamento desses alunos acelerados nas séries seguintes. Além disso, a falta de avaliação do processo de implementação da aceleração de ensino o deixa vulnerável a especulações e opiniões leigas. Portanto, examinar como ocorre a aceleração dos alunos superdotados pode ajudar a pontuar acertos e falhas no emprego de tal prática, principalmente, no contexto brasileiro, no qual não há pesquisas a respeito dos efeitos desse procedimento educacional.

Decisões sobre aceleração de alunos têm sido tomadas, no Brasil, com base no direito do aluno ao avanço de série em qualquer idade escolar. Esse direito está estabelecido pela Lei de Diretrizes e Bases da Educação Nacional, de 1996 - LDBEN (Ministério da Educação, 1996) - quando atesta a garantia de acesso aos níveis mais elevados do ensino, da pesquisa e da criação artística, segundo a capacidade de cada um, e assegura aos alunos superdotados a possibilidade de aceleração para concluir em menor tempo o programa escolar -, bem como por documentos orientadores da Educação Especial (Ministério da Educação, 2001, 2004, 2008), que oferecem uma ampliação das possibilidades de atendimento ao superdotado. No entanto, 
não há regulamentação, por parte dos estados e municípios, acerca da implementação da ação pedagógica de aceleração de ensino de maneira a cumprir decisões legais. A ausência de regulamentação legal sobre procedimentos de aceleração transfere para a escola a responsabilidade de decidir em que condições a criança poderá ou não ser promovida e qual tipo de acompanhamento será necessário. Como consequência, tal decisão, em muitos casos, pode ser baseada em critérios subjetivos, nem sempre apoiados no que a literatura recomenda. A implementação da aceleração de ensino não deve ser conduzida de maneira intuitiva, sem um referencial teórico que oriente as ações e sem uma avaliação das necessidades e interesses do aluno e das características da escola (Alencar \& Fleith, 2001; Colangelo et al., 2004; Rogers, 2004, 2007).

Este estudo, de caráter exploratório, teve como objetivo examinar a percepção de alunos superdotados do ensino fundamental, que foram submetidos a procedimentos de aceleração de ensino quando frequentavam a educação infantil, suas mães e professores acerca dessa prática.

\section{MÉTODO}

\section{Participantes}

Participaram do estudo 12 alunos superdotados, sendo duas meninas e dez meninos. À época da coleta de dados, oito frequentavam escolas públicas, e quatro eram de escolas particulares. Três alunos frequentavam o $6^{\circ}$ ano, dois cursavam o $5^{\circ}$ ano, quatro frequentavam o $4^{\circ}$ ano, dois cursavam o $3^{\circ}$ ano e um estava no $2^{\circ}$ ano do ensino fundamental. Entre os participantes, cinco alunos foram acelerados mais de uma vez. Quanto à posição funcional na família, um era filho único, cinco eram primogênitos e seis eram os caçulas. A idade média era de 8,08 anos, variando entre $6 \mathrm{e}$ 10 anos. Os estudantes foram indicados por professores de salas de recursos do Atendimento Educacional Especializado ao Aluno com Altas Habilidades/Superdotação de uma secretaria de educação da região centro-oeste com base em dois critérios: frequentar o atendimento e ter passado por processo de aceleração de ensino durante os anos da pré-escola ou no $1^{\circ}$ ano do ensino fundamental.

Também participaram do estudo 12 mães, 10 professores da sala de aula regular e cinco professores que atuavam nas salas de recursos frequentadas pelos alunos participantes. A maioria das mães era casada ou tinha uma união estável com tempo de convivência em média de 13 anos (variando entre 9 e 25 anos). A idade média das mães era de 36,8 anos (variando entre 28 e 47 anos). Em relação à escolaridade, três tinham concluído o ensino fundamental, quatro o ensino médio, três o ensino superior, uma o superior incompleto e uma cursou uma pós-graduação. Quanto às profissões, foram informadas as seguintes: professora de matemática, cabeleireira, diarista, bancária, técnica em segurança do trabalho, empregada doméstica, funcionária de serviços gerais e secretária do lar $(n=5)$. A renda familiar era, em média, de R $\$ 3.790,00$, variando entre $\mathrm{R} \$ 800,00$ e R $\$ 10.000,00$.

Os professores regentes participantes da pesquisa, nove mulheres e um homem, eram os que ministravam as disciplinas nas quais os alunos demonstravam habilidade. Sete professoras eram formadas em pedagogia, duas em letras e um professor tinha cursado biologia. Sete deles concluíram cursos de pósgraduação nas áreas de psicopedagogia $(n=4)$, avaliação de aprendizagem, filosofia e administração escolar. Esses professores tinham, em média, 34,3 anos de idade (variando entre 26 e 50 anos), atuavam como professores, em média, há 13 anos (variando entre 3 e 25 anos de experiência) e ministravam aulas em turmas com uma média de 27,6 alunos (variando entre 15 e 38 alunos por sala de aula). A maioria dos professores informou não ter conhecimento ou ter participado de cursos sobre superdotação, sendo que três deles afirmaram ter assistido uma palestra sobre o assunto.

Quanto aos professores da sala de recursos, quatro mulheres e um homem, a idade média era de 39,4 anos (variando entre 30 e 45 anos de idade). Eles tinham cerca de 15,4 anos de experiência como professores (variando entre 8 e 25 anos) e atuavam no programa para superdotados em média há 7,2 anos (variando entre 5 e 10 anos de experiência). Três professores tinham cursado pedagogia e dois eram formados em estudos sociais. Todos tinham participado dos vários cursos sobre o tema superdotação, oferecidos pela secretaria de educação na qual atuavam. Dois professores tinham pós-graduação em pedagogia e dois concluíram um curso de pós-graduação sobre alunos bem-dotados. Os professores atendiam entre 4 a 12 alunos, por período do dia, uma vez por semana. 


\section{Instrumentos e Procedimentos}

Entrevistas semiestruturadas foram conduzidas com os alunos que passaram pelo processo de aceleração durante a educação infantil, mães e professores, com a finalidade de investigar a percepção acerca da aceleração de ensino. O roteiro de entrevista incluiu questões sobre descrição e avaliação do processo de aceleração, adaptação à série avançada, relacionamento com os pares, entre outros. Após aprovação do projeto por um Comitê de Ética em Pesquisa, a primeira autora entrou em contato pelo telefone com os professores e pais dos 12 alunos superdotados para informálos sobre os objetivos do estudo e convidá-los a participar da pesquisa. Depois de preenchidos os termos de consentimento livre e esclarecido, foram agendados encontros com os participantes do estudo. As entrevistas foram realizadas individualmente, com duração média de 15 minutos para os alunos e de 30 para mães e docentes. No caso de duas mães, depois de faltarem a quatro encontros consecutivos, optou-se por fazer a entrevista pelo telefone. A maioria das entrevistas foi realizada na escola regular ou na escola que abrigava a sala de recursos. Encontros com duas mães foram realizados na residência da família. Todas as entrevistas foram gravadas e posteriormente transcritas na íntegra.

\section{Análise de Dados}

Utilizou-se a análise de conteúdo para examinar os dados das entrevistas (Bardin, 1977). A unidade de registro foi o tema - núcleo de sentido que compõe a comunicação -, cuja presença ou frequência de aparição trouxe um significado relevante para o objetivo da investigação. A frequência foi considerada como regra de enumeração e as categorias construídas a partir do agrupamento dos temas retirados da fala do entrevistado. A análise se completou com a relação estabelecida entre as categorias produzidas. Para garantir a fidedignidade dos dados, as técnicas empregadas foram: exame e reexame dos dados, apontamentos da pesquisadora e triangulação das fontes de informação (Marshall \& Rossman, 1995).

\section{RESULTADOS}

\section{Percepção de Professores da Sala de Aula Regular e da Sala de Recursos}

Perguntou-se, inicialmente, aos professores de sala de aula regular (identificados pela sigla PR) se eles tinham conhecimento de que seus alunos haviam passado pelo processo de aceleração de ensino quando frequentavam a educação infantil. Três professores afirmaram que não sabiam que seus alunos tinham sido acelerados e sete responderam afirmativamente. Esses sete professores obtiveram a informação por meio de profissionais da escola, como diretores e outros professores $(n=5)$, ou por meio da família $(n=1)$ ou do próprio aluno $(n=1)$. Seguem alguns relatos dos professores:

Eu não sabia. Ele pulou o jardim três? Então talvez seja até por isso que a letrinha dele ainda não se acomodou, o que não interfere na aprendizagem dele. (PR7)

A única coisa que foi passado nas reuniões que ele é um aluno que sobressaía e optaram por acelerá-lo. (PR10)

Eu só sei porque na primeira reunião a mãe me fez a colocação de que ele havia sido promovido e que ela sabia da imaturidade dele. Foi através dela que eu fui informada. Mas eu não sei mais detalhes. (PR1)

Quando eu peguei ele na quarta série, estranhei Esse menino deveria estar na terceira! - ele mesmo falou que tinha pulado uma série. (PR2)

Tanto professores de sala de aula regular quanto de sala de recursos (identificados pela sigla PSR) associaram a prática de aceleração de ensino exclusivamente à modalidade específica pela qual seus alunos tinham passado - o avanço de série. Apenas a PSR 3 afirmou que, quando o aluno está desestimulado, pode ser oferecida "uma adequação curricular de um determinado conteúdo". Os professores foram ainda indagados sobre a percepção que tinham da aceleração de ensino. As respostas versaram sobre condições para implementação da prática e avaliação da mesma, apresentadas nas duas subseções seguintes.

\section{Condições para implementação da aceleração}

Segundo os docentes, as condições dependem de um conjunto de características pessoais apresentadas 
pelos alunos, bem como da adoção de procedimentos específicos. No que se refere às características dos alunos, as respostas foram agrupadas em:

(a) Características cognitivas: habilidade acima da média nas áreas acadêmicas, elevada capacidade de aprendizagem, domínio do conteúdo programático e bom desempenho acadêmico. Exemplo de relatos: "ou você acelera o aluno porque o aluno está na série errada, devido à capacidade dele. Aí, coloca ele numa série melhor" (PR10), "Quando o aluno tem mais conhecimento sobre o conteúdo que está sendo trabalhado na escola" (PSR1), "Se o aluno cumpriu a parte cognitiva, acho que pode ir para frente, porque pode se desestimular e ter sub-rendimento" (PRS3).

(b) Maturidade emocional. Exemplo de depoimentos: "A gente tem a noção de que muitas vezes essa promoção não vem acompanhada da maturidade em si. A criança tem que ser madura para ir para frente pular o ano" (PR2), "A parte emocional tem que estar boa... se tiver maturidade não tem problema" (PSR 4).

(c) Bom relacionamento com os pares. Exemplos: "Ele era pequeno em relação aos colegas e acho que talvez ele tenha tido problemas com a questão da maturidade e aceitação. Teve que ser dado um apoio para que ele se desenvolvesse bem com o novo grupo de amigos" (PSR1), "Tem que avaliar não só os aspectos cognitivos, mas o aspecto social e de maturidade" (PR2), "Ela pode encontrar colegas mais velhos com outros interesses" (PSR5).

(d) Interesses ou motivação para aprender. Exemplos: "Ele dominava bastante o conteúdo e as atividades não estavam mais interessantes" (PR1), "Ele precisa de algo para satisfazer seus interesses porque pode se desestimular e ter sub-rendimento" (PSR3).

Apenas um professor da sala de aula regular afirmou que são muito raros os casos de crianças que podem ser aceleradas. A percepção da aceleração de ensino por parte dos professores também esteve atrelada aos procedimentos necessários para a implementação exitosa da prática.

(a) Avaliação e acompanhamento do aluno na nova turma: avaliar como o aluno se desenvolve na nova turma em termos socioemocionais e de aprendiza- gem. Exemplos de relatos são: "tem que acompanhar, né?" (PR3), "A falta de acompanhamento é que prejudicou" (PSR2), "Teve que ser dado um apoio para que ele se desenvolvesse bem" (PSR1), "Me pediram para que eu ficasse como ouvinte com ele, e ele ficasse como ouvinte comigo e durante mais ou menos, 15 a 20 dias, ele conseguiu acompanhar o desenvolvimento da sala. Permaneceu durante um mês, ele fez uma prova com caráter avaliativo, ele conseguiu ter um bom desempenho, aí, ele teve a promoção" (PR1).

(b) Preparação do professor para lidar com o aluno acelerado. Como por exemplo: "A gente tem que estar preparado porque essa prática sempre acontece com nossos alunos" (PSR2).

Observa-se que a maior parte das respostas fornecidas pelos professores condicionou a adoção ou não da aceleração de ensino ao desempenho acadêmico e habilidades cognitivas superiores, além de maturidade emocional. $\mathrm{O}$ acompanhamento do aluno acelerado em sua nova turma, também, parece ser condição essencial para o sucesso da prática e desenvolvimento do aluno.

Os professores regulares foram indagados acerca de como eram orientados, na escola onde lecionavam, sobre os procedimentos de avanço de série. Três professores afirmaram que em suas escolas não existe nenhuma orientação ou regulamento interno que indique como implementar a aceleração de ensino ou, especificamente, o avanço de série. Sete professores informaram que as escolas onde lecionam já lançaram mão dessa prática. No entanto, existem poucas orientações e suporte institucional ao professor na implementação da aceleração. De acordo com esses sete professores, o aluno pode ser candidato à aceleração quando se destacar em termos de domínio do conteúdo programático. Cabe à própria professora, após observação do desempenho superior, indicar o avanço de série ou aplicar testes de conhecimento para essa aceleração: "Geralmente, elas observam se tem um aluno que está se destacando muito para ser promovido" (PR1), "O aluno passou por uma avaliação, uma prova escrita, mostrando o conhecimento teórico e depois foi para a outra série" (PR12). Em outros casos, a professora pede orientação à direção ou coordenação da escola, procura os pais para uma conversa ou, ainda, encaminha o aluno para a equipe psicopedagógica do programa de atendimento ao aluno com altas habi- 
lidades. "A gente leva o caso para a direção" (PR1), "Geralmente se conversa com os pais" (PR2); "Além dela, indiquei outros alunos também que iam mandar para um atendimento, para testes, depois iria voltar aqui pra escola" (PR9). Três professores destacaram a necessidade de um apoio institucional para sua tomada de decisão relacionada ao avanço de série. Para eles é importante o apoio de uma equipe psicopedagógica com profissionais que possam avaliar os alunos e aconselhar professores e familiares. Duas professoras mencionaram a existência de pareceres ou leis que regulamentam o processo de aceleração de ensino.

Da mesma forma, foram ressaltadas barreiras encontradas pelos professores referentes à implementação do avanço de série. Dois professores reclamaram sobre a existência de grupos fechados ou a resistência dos profissionais da escola em relação a essa prática de ensino: "Aqui o grupo não gosta de fazer essa aceleração por qualquer coisa ou precipitadamente" (PR7), "Acredito que não se adote mais esse critério tão facilmente aqui na escola devido a algumas experiências pouco bem-sucedidas que tivemos" (PR12).

\section{Avaliação docente da aceleração de ensino}

As respostas relativas à avaliação da prática de aceleração indicaram mais argumentos desfavoráveis do que favoráveis tanto da parte dos professores da sala de aula regular quanto da sala de recursos. Os argumentos favoráveis ( $n=7$, sendo quatro de PR e três de PSR) estavam calcados no desempenho acadêmico acima da média ou na necessidade de se atender aos interesses dos alunos. Alguns relatos dos professores ilustram suas avaliações:

Se ele sabe o conteúdo e pode se adaptar socialmente, pode ser promovido. Ele pode render mais do que em uma série em que não tem motivação alguma. (PSR1)

Eu acho um procedimento muito válido, porque se a criança demonstra desempenho e acerta tudo, acerta a maturidade ... é importante, eu acredito que seja importante e necessário. Ela tem uma capacidade maior que não é estimulada. (PR11)

Ele precisa de algo para satisfazer seus interesses. $\mathrm{Na}$ outra série ele pode ter outros desafios, isso complementa uma necessidade que ele tem. Deve ser estimulado naquilo que ele é melhor. (PSR3)
No caso da aluna A., ela foi acelerada porque ela tem um desempenho além. Neste caso, então, eu concordo. Seria um desperdício deixar o aluno naquela série mesmo. Se ele tem uma capacidade de enfrentar uma série maior. (PR9)

Os argumentos desfavoráveis ( $n=22$, sendo 12 de PR e 10 de PRS) estavam associados a possíveis problemas de adaptação dos alunos acelerados nas séries seguintes, tais como:

(a) A falta de maturidade emocional da criança pode levá-lo à desadaptação social $(n=16$, sendo nove de PR e sete de PSR): "Muitas vezes essa promoção não vem acompanhada da maturidade em si. E se ela não vier, é algo que vai se arrastando" (PR1), "Não sou a favor da aceleração, só em alguns casos [...] eu acho que a maturidade da criança fica muito comprometida" (PR7), "Percebi assim, esse sofrimento da criança de estar sempre um pouquinho aquém dos outros em termos de maturidade" (PR12), "A parte emocional tem que estar boa. Ela tem que estar madura" (PSR4), "Percebo às vezes que os alunos apresentam comportamento que chamam a atenção ou pelo excesso ou pela falta, ou pela carência" (PR12). "Não adianta acelerar a criança da primeira para a terceira série e ela continuar com as brincadeiras e a maneira de agir da primeira" (PSR4).

(b) A aceleração gera dificuldades acadêmicas em anos subsequentes ou em outras áreas de conhecimento: "Eu creio que se a criança está se desenvolvendo bem naquela série, ela deve se manter ali, para que mais tarde ela não venha a ter, por exemplo, essa dificuldade que o aluno B. está tendo na produção de texto" (PR7), "Depois ele teve problemas de escrita porque a alfabetização dele não tinha sido boa" (PRS2).

(c) A aceleração produz expectativas nos pais e professores de que as crianças apresentarão desempenho superior. Como consequência, os alunos se sentem pressionados e cobrados: "Às vezes colocam uma expectativa muito grande em cima da criança. Não é só saber ler e escrever" (PSR5).

(d) A diferença de interesses como resultado da diferença de idade. O aluno pode se deparar com colegas de classe que apresentam interesses distintos dos seus: "Tem também a questão da maturidade, pode ter um choque de interesses. Ela pode encon- 
trar colegas mais velhos com outros interesses.... $e$ outras vontades" (PSR5).

(e) Relação idade/série: o aluno deve estar na classe de acordo com a idade: "se não tiver um atraso na idade eu acho que não é ideal não. Ele deve ficar na série que está" (PR7).

Uma professora de sala de aula regular não é a favor nem contra a aceleração de ensino. Para ela, depende do caso: "existem situações e situações" (PR9).

\section{Percepção de Mães e Alunos}

A maioria das mães $(n=11)$ destacou o papel da professora da educação infantil na indicação do avanço de série ao aluno. Entretanto, em nove casos, essa indicação foi feita em parceria com a mãe $(n=2)$, profissionais da equipe escolar $(n=5)$, psicólogo $(n=1)$ e mãe e pediatra $(n=1)$. Apenas duas mães informaram que a iniciativa foi exclusivamente da professora $\mathrm{e}$ uma mãe afirmou que a diretora da escola tomou a decisão. Seguem alguns exemplos de relatos de mães (identificadas pela sigla $\mathrm{M}$ ):

Ele adiantou do jardim 1, 2, ele passou pro primeiro ano. E quando ele chegou no primeiro ano elas passaram ele para o segundo ano, a professora junto com a coordenadora, elas que decidiram. (M1)

A diretora me chamou na escola, e disse que meu filho não podia ficar no jardim 1. (M4)

A professora é que abraçou a causa, ela não conhecia a sala de recursos e começou a pesquisar, nós estudamos e gente acabou encontrando junto. Ela ajudou muito. (M12)

Eu descobri que ele era assim, porque fui fazer uma consulta no HMIB, pré-natal e levei ele. Uma psicóloga sentada do lado estava com um livro sobre órgãos humanos... e ele foi ler. Ele estava lendo e eu não estava entendo nada... A psicóloga perguntou qual a idade dele, eu falei cinco anos... Ela disse que ele precisava de um colégio especial... e escreveu uma carta para a professora dele para que ela pudesse me ajudar com um colégio mais avançado para ele. (M5)

Quando tinha 1 ano e 2 meses, foi a pediatra que falou que o comportamento dele era muito além do que o comportamento de uma criança da idade dele... quando ele começou a falar e a pediatra ficou pasma. E ela me deu um encaminhamento para poder procurar uma escola especial... Ele entrou na escola pública com quatro anos, no pré. Passou uma semana, a professora me chamou, falou que ela não tinha condições de ficar com ele na sala porque ele não acompanhava as atividades da série, estava além. (M12)

Foi na escola pública aonde o professor observou essa necessidade que ele tinha de desenvolver mais. (M7)

A professora veio e falou pra mim - 'mãe, não dá pra ficar com ele na sala, ...porque ele vai ser prejudicado, se você aceitar eu vou passar ele'. (M10)

Tanto mães quanto alunos (identificados pela sigla A) consideraram que os motivos para aceleração de ensino estavam relacionados (a) ao conhecimento do aluno acima da média dos pares (domínio do conteúdo escolar em relação à turma ou domínio da leitura e da escrita) ( $n=17$, sendo nove motivos apresentados pelas mães e oito pelos alunos); (b) ao comportamento do aluno em sala de aula (não interagia com as crianças de sua sala de aula porque elas não tinham os mesmos interesses do que ele ou porque terminava os trabalhos antes dos colegas e atrapalhava a professora) $(n=6$, sendo quatro motivos apresentados pelas mães e dois pelos alunos); e (c) à falta de motivação em sala de aula $(n=4$, três motivos mencionados pelas mães e um pelo aluno). Seguem exemplos dos relatos:

Era preciso avançar, porque senão ele não ia atrasar, porque ele sabia muito para estar ali naquela série. Aí aceleraram ele. (M8)

Todo o currículo que era colocado ele já sabia. (M6)

Naquela época tinham que formar frases e ele já fazia textos, ler um parágrafo. Ele já lia o livro todo, tabuada, ele já sabia a tabuada toda, já sabia as quatro operações. (M6)

Com três anos ele já sabia ler. (M12)

Ela chegava em casa, ficava reclamando que as coisas estavam muito fáceis, ela nunca teve que pensar, ela pegava as coisas e resolvia. (M11)

A professora disse que sou mais adiantada, acho que vou pular de ano de novo, ela falou. (A11)

Desde 1 ano e meio eu já sabia ler. (A5) 
Eu já sabia ler, escrever, fazer contas e um monte de coisa. (A8)

Ele não estava interagindo com as outras crianças, justamente porque as outras tinham interesse de desenhar, pintar, cantar e ele não. Ele queria ler e escrever. (M4)

Eu respondia tudo... e atrapalhava a professora. (A3)

Ele corrigia as outras crianças e era aquele tumulto na sala. (M12)

Quatro mães informaram que para serem acelerados, seus filhos tiveram que ser avaliados pela equipe psicopedagógica do Atendimento Educacional Especializado ao Aluno com Altas Habilidades/Superdotação. Outras quatro destacaram que seus filhos já vinham sendo observados pela equipe da escola e considerados para aceleração.

Eles fizeram muita prova com ele para ver mesmo se ele tinha capacidade de passar pra outra série que ele está hoje... a professora mandou ele para essa sala de recursos. E aí, aqui na escola fizeram os testes com ele e elas mesmo passaram ele. (M5)

O professor observou essa necessidade que ele tinha de desenvolver mais... ele encaminhou para fazer os testes (na sala de recursos) e falou pra gente que ele poderia ser uma criança com altas habilidades. (M7)

Os professores anteriores já avisavam os outros "ó, ele é assim, assim” - os professores já observavam e coisa de duas semanas já viam e aí adiantaram ele. (M8)

Foi ainda perguntado às mães se houve necessidade de recorrer a processo jurídico para que seus filhos fossem avançados de série. As 12 mães informaram que não. Entretanto, uma mãe declarou que teve que seguir os trâmites administrativos de acordo com a Secretaria de Estado de Educação e assinar alguns documentos. Outra questão feita às mães foi acerca do conhecimento que elas tinham sobre a legislação educacional que favorece os procedimentos de aceleração de ensino de alunos superdotados. Apenas duas mães responderam positivamente. A mãe 3 relatou que recebeu informações de um professor e a mãe 1 que informou já ter participado de uma audiência pública no Senado Federal que discutia o atendimento educacional do aluno superdotado.
Os superdotados avaliaram a experiência de aceleração, de maneira geral, como positiva. Segundo nove alunos, a passagem para a série seguinte ocorreu sem problemas, embora quatro deles tenham mencionado uma dificuldade inicial, logo depois superada, pelo fato de não conhecerem os novos colegas. Nove alunos relataram, ainda, que foram muito bem recebidos pelos colegas e professoras da nova turma. Apenas três alunos informaram que o ingresso na série seguinte foi difícil porque não sabiam a letra cursiva ou porque a professora era brava:

Não tive problemas, foi fácil. (A1)

Foi bom. Fiquei junto com minha irmã... a gente ia para a piscina. (A2)

A professora foi legal. (A10)

Foi legal, foi normal... a professora falou com o diretor e eu fui para a $1^{a}$ série. (A5)

Foi normal, eu brincava com os meninos e tinha a minha prima. (A4)

Meus amigos me receberam bem, não tive problemas. (A2)

Foi normal, meus amigos gostaram de mim. (A8)

Nos primeiros dias foi estranho, eu era nova na escola, mas depois foi normal. (A9)

Fiquei um pouco com medo, mas aí deu tudo certo. (A7)

Quando eu não sabia a letra cursiva a professora me ajudava. (A3)

A avaliação das mães sobre o processo de aceleração de ensino de seus filhos também foi positiva. À época da coleta de dados, as mães afirmaram que seus filhos não apresentavam dificuldades na escola, acompanhavam a turma e tinham um bom desempenho acadêmico e muitos amigos, e se sentiam estimulados a aprender mais. Seguem exemplos de relatos:

Até hoje a gente não teve dificuldade nenhuma, ele se sente bem porque ele está na mesma série que a irmã, que é onze meses mais velha e se sente de igual pra igual. (M2) 
Acho que foi bom, não atrapalhou em nada ele, não tem dificuldade nenhuma, pra mim está bom até agora não prejudicou ele em nada. (M10)

Eu acho incrível a capacidade que ele tem, tudo que ele aprende, ele pega de primeira. Foi bom, se ele não tivesse sido acelerado ele teria tido prejuízo. (M8)

Ele não enfrenta dificuldades nas matérias, tira notas ótimas. (M3)

Aqui ele tem muitos amigos, começou a interagir melhor com as outras crianças. (M4)

Ele brinca direito com os amigos, não tem problema nenhum de adaptação, é muito comunicativo, com todo mundo. (M10)

Ela se sentiu mais incentivada, estimulada, ela gosta. (M11)

Ele não se sentiu excluído, porque tinham os mesmos interesses, falavam da mesma coisa e já escreviam como ele. (M4)

Apenas uma mãe informou que seu filho apresentava, à época da coleta de dados, problemas com a letra e, por isso, tinha dificuldade na produção de textos - "Ele tem pavor de produção de texto... a professora colocava no caderno dele: "sua letra é horrível" - ele tem dificuldade de formular a letra direitinho" (M7). Em síntese, os resultados indicam uma percepção positiva tanto de alunos quanto de mães no que se refere à prática de aceleração de ensino.

\section{DISCUSSÃO}

A experiência de aceleração foi avaliada, de maneira geral, como positiva por mães e alunos. $\mathrm{O}$ bom acolhimento por parte dos colegas de sala pode ter contribuído para o sucesso das relações sociais, do ajustamento à nova turma e do próprio avanço de série. Especialistas discutem que quando a criança superdotada é acelerada, existe a possibilidade de que encontre pares com interesses semelhantes e a tendência é a de que haja melhor interação entre eles (Colangelo \& Assouline, 2005; Oliveira, 2007; Rogers, 2007). Sobre esse aspecto, Kleinbok e Vidergor (2009) sugerem que a classe seja informada sobre o novo colega para que não ocorram problemas, em especial de bullying.
Outra questão controversa se apresenta quando a criança é capaz de acompanhar o conteúdo da série para a qual foi acelerada, no entanto, ainda não tem o domínio da letra cursiva. Apenas dois alunos relataram dificuldades no uso da letra cursiva quando avançaram de série. Uma professora da sala de recursos e três professores da sala de aula regular afirmaram que seus alunos "tinham a letra feia". Esse resultado pode apontar a tendência que os professores têm de supervalorizar o formato da letra escrita, mais do que o conteúdo ou ritmo de aprendizagem do aluno. Terrassier (1979) afirma que não é raro o superdotado aprender a ler em idade precoce, encontrando, porém, dificuldades na área da escrita. Ademais, é mais frequente observar essa discrepância entre o nível mental e psicomotor, sobretudo em meninos, acarretando uma frustração pela falta de habilidade em usar as mãos na mesma velocidade do pensamento. Esse descompasso pode gerar ansiedade e desconforto, que os leva a apresentar uma produção escrita ainda mais irregular. Outros pesquisadores da área alertam que é comum ocorrer uma assincronia entre o desenvolvimento intelectual, psicomotor, linguístico e perceptual (Aspesi, 2003; Roeper, 1982; Silverman, 2002). Aspesi (2003) observa que problemas de aprendizagem podem ocorrer a partir da falta de percepção dos professores sobre a assincronia entre o desenvolvimento cognitivo e físico da criança superdotada. Esta autora argumenta que um aluno pode apresentar leitura precoce ao mesmo tempo que seu desenvolvimento psicomotor não permite a manipulação de um lápis ao escrever. Nesse sentido, é fundamental que professores ofereçam recursos diversificados para produção e apresentação de texto, tais como apresentação oral, dramatização, jogo, brincadeira, trabalho em dupla, e, também, incentivos para aprimoramento da escrita. Além disso, atividades de produção, organização, fluência e originalidade de ideias deveriam ser mais valorizadas.

Quando questionados sobre o que entendiam por aceleração de ensino, os professores entrevistados vincularam a aceleração exclusivamente ao avanço de série, parecendo desconhecer outras modalidades dessa prática, como, por exemplo, compactação curricular (estratégia que permite que se molde ou se adapte o currículo regular no sentido de minimizar a dissonância entre as propostas curriculares e os interesses do aluno), aceleração em apenas uma disciplina e tutoria (Maia-Pinto \& Fleith, 2012; Rogers, 2004, 2007). Esse conhecimento limitado pode gerar con- 
cepções equivocadas e estereotipadas acerca da aceleração, resistência na sua adoção, bem como inibir o uso de formas alternativas de atendimento às necessidades de aprofundamento e enriquecimento curricular dos alunos superdotados.

Os resultados do presente estudo indicaram uma postura desfavorável dos professores da sala de aula regular e da sala de recursos quando indagados sobre a aceleração, embora tenham reconhecido o bom desempenho acadêmico e a facilidade de interação social de seus alunos superdotados acelerados. Entre os argumentos mais mencionados pelos professores estavam a falta de maturidade emocional do aluno e as possíveis dificuldades acadêmicas em anos subsequentes ou em outras áreas de conhecimento, o que não ocorreu com os alunos desta pesquisa. Concepções dos docentes acerca da aprendizagem como um processo vertical e linear, que depende de prérequisitos para se passar de um estágio para outro, são possíveis explicações para tais achados. A aquisição de uma grande bagagem de informação parece ser mais valorizada no contexto escolar do que o desenvolvimento de competências e a atenção aos interesses e estilos de aprendizagem do aluno. Também, crenças em relação ao papel do professor em sala de aula como o condutor do processo de ensino-aprendizagem e o do aluno, como ser passivo na sua trajetória escolar, podem nos ajudar a compreender esses dados. Outro aspecto a ser questionado é como avaliar e garantir que a criança está madura emocionalmente e "pronta" para avançar de série. A ausência de evidências empíricas que contraindiquem a prática da aceleração é um fato pouco divulgado entre gestores, docentes e pais, abrindo espaço para veiculação de argumentos de senso comum. $\mathrm{O}$ que se pode concluir é que, mesmo trabalhando com alunos que foram acelerados, os professores ainda têm poucas informações referentes à aceleração de ensino. $\mathrm{O}$ avanço de série não é uma estratégia em que o aluno é apenas repassado para a série seguinte e submetido a um ensino padronizado com pouca atenção ao desenvolvimento de suas características. Especialistas ressaltam que é fundamental um planejamento, acompanhamento e avaliação da implementação dessa prática (Alencar \& Fleith, 2001; Colangelo et al., 2004; Hoogeveen et al., 2009; Howley, 2002; Lee et al., 2010; Pérez, 2009).

A maioria dos professores das salas regulares entrevistados informou que nas escolas onde trabalham não havia regras específicas, instrumentos ou proce- dimentos que apoiassem a implementação da aceleração. Neste sentido, percebe-se a dificuldade por parte dos docentes, e da escola em geral, na adoção dessa prática. A falta de sistematização de processos pedagógicos e administrativos corrobora a ação informal dos professores relacionadas à adoção dos procedimentos de aceleração. É importante avaliar como a aceleração será planejada e implementada. Isso implica examinar as habilidades cognitivas e as características emocionais e sociais do aluno que poderá ser acelerado, a concepção de superdotação adotada pela escola, a receptividade, bem como o preparo do professor (e da turma) para receber um aluno mais novo e com potencial superior (Alencar \& Fleith, 2001; Colangelo et al., 2004; Maia-Pinto \& Fleith, 2012).

Os resultados desse estudo revelaram que o processo de aceleração dos alunos superdotados durante a educação infantil foi recomendado, principalmente, pelas professoras da pré-escola. Ressalta-se, portanto, a importância de se incluir na formação inicial e continuada dos professores informações sobre superdotação e aceleração, de forma que um número maior de alunos com alto potencial possa ser atendido conforme suas necessidades. Renzulli (1998) afirma que um ambiente com recursos e profissionais bem preparados aumenta as chances tanto de desenvolvimento de comportamentos de superdotação, quanto de descoberta de novos talentos. Os motivos para aceleração foram relatados pelas mães e alunos como conhecimento mais avançado sobre o conteúdo escolar, facilidade de comunicação ou linguagem oral avançada, desmotivação e pouca interação com colegas em sala de aula. Domínio do conteúdo, currículo pouco desafiador e limitado relacionamento com pares que não apresentam interesses semelhantes têm sido razões frequentemente apontadas pelos especialistas para aceleração de ensino (Colangelo et al., 2004; Rogers, 2007). A ausência de informação, por parte do professor, quanto à legislação referente à aceleração de ensino foi outro dado encontrado nesta pesquisa. Cabe lembrar a responsabilidade da escola no que diz respeito ao desenvolvimento e educação do aluno, representada em sala de aula por seu professor. Nesse sentido, o conhecimento acerca da lei que norteia seu trabalho é imprescindível. Por outro lado, a ausência de regulamentação legal da aceleração promove uma lacuna entre o que se pode fazer do ponto de vista educacional para atender às necessidades do aluno superdotado, uma vez que a lei maior autoriza a aceleração de ensino, e o que efetivamente se faz. 
Como limitações deste estudo, podem ser apontados o número limitado de participantes, possíveis lapsos, por parte de mães e alunos, na recordação de fatos pertinentes ao processo de aceleração ocorrido há anos, e a impossibilidade de se entrevistar os professores responsáveis pelo avanço de série dos alunos participantes e de se conhecer em detalhes como ocorreu a implementação da aceleração. Por outro lado, o estudo traz luz a uma temática relevante e pouco investigada no Brasil, sob quatro olhares - do aluno superdotado, da mãe, do professor da sala de aula regular e da sala de recursos. Para pesquisas futuras, sugere-se (a) comparar alunos superdotados que entraram precocemente no $1^{\circ}$ ano do ensino fundamental e os que não o fizeram quanto ao desempenho acadêmico, motivação para aprender e características cognitivas e socioemocionais; (b) realizar um estudo longitudinal com alunos superdotados acelerados na educação infantil com vistas a avaliar efeitos da prática sobre o desenvolvimento do aprendiz ao longo de sua vida escolar; (c) examinar a percepção dos pares em relação ao avanço de série e sobre o colega superdotado acelerado; e (d) investigar situações em que a aceleração de alunos superdotados teve efeitos negativos, com vistas a identificar fatores que interferiram no processo.

\section{REFERÊNCIAS}

Alencar, E. M. L. S., \& Fleith, D. S. (2001). Superdotados: Determinantes, educação e ajustamento. São Paulo: EPU.

Alencar, E. M. L. S., \& Fleith, D. S. (2006). A atenção ao aluno que se destaca por um potencial superior. Revista de Educação Especial, 27, 19-31.

Aspesi, C. C. (2003). Processos familiares relacionados ao desenvolvimento de comportamentos de superdotação em crianças de idade pré-escolar (Dissertação de mestrado). Universidade de Brasília, Brasília.

Bardin, L. (1977). Análise de conteúdo. Lisboa, Portugal: Edições 70.

Colangelo, N., \& Assouline, S. G. (2005). Accelerating gifted children. Principal, 84, 62.

Colangelo, N., Assouline, S. G., \& Gross, M. U. M. (Eds.). (2004). A nation deceived: How schools hold back America's brightest students (Vol. I). Iowa City, IA: The Connie Belin \& Jacqueline N. Blank International Center for Gifted and Talented Development.

Delou, C. M. C. (2001). Sucesso e fracasso escolar de alunos considerados superdotados: Um estudo sobre a tra- jetória escolar de alunos que receberam atendimento em salas de recursos de escolas da rede pública de ensino (Tese de doutorado). Pontifícia Universidade Católica de São Paulo, São Paulo.

Diezmann, C. M., Watters, J. J., \& Fox, K. (2001). Early entry to school in Australia: Rhetoric, research and reality. Australian Journal for Gifted Education, 10, 5-18.

Hoogeveen, L., Hell, J. G., \& Verhoeven, L. (2009). Selfconcept and social status of accelerated and nonaccelerated students in the first 2 years if secondary school in the Netherlands. Gifted Child Quarterly, 53, 50-67.

Howley, A. (2002). The progress of gifted students in a rural district that emphasized acceleration strategies. Roeper Review, 24, 158-160.

Kleinbok, O., \& Vidergor, H. (2009). Grade skipping: A retrospective case study on academic and social implications. Gifted and Talented International, 24, 21-38.

Lee, S-Y., \& Olszewski-Kubilius, P. (2006). A study of instructional methods used in fast-paced classes. Gifted Child Quarterly, 50, 216-237.

Lee, S-Y., Olszewski-Kubilius, P., \& Peternel, G. (2010). The efficacy of academic acceleration for gifted minority students. Gifted Child Quarterly, 54, 189-208.

Lubinski, D. (2004). Long-term effects of educational acceleration. In N. Colangelo, S. G. Assouline, \& M. U. M. Gross (Eds.), A nation deceived: How schools hold back America's brightest students (Vol. II, pp. 23-38). Iowa City, IA: The Connie Belin \& Jacqueline N. Blank International Center for Gifted and Talented Development.

Ma, X. (2003). Effects of early acceleration of students in mathematics and attitudes toward mathematics and mathematics anxiety. Teachers College Records, 105, 438-464.

Maia-Pinto, R. R., \& Fleith, D. S. (2012). Aceleración de la enseñanza para alumnos superdotados: Argumentos favorables y contrarios. Revista de Psicología, 30, 189214.

Marshall, C., \& Rossman, G. B. (1995). Designing qualitative research. Thousand Oaks, CA: Sage.

Merry, M. S. (2008). Educational justice and the gifted. Theory and Research in Education, 6, 47-70.

Ministério da Educação. (1996). Lei de Diretrizes e Bases da Educação Nacional - LDBEN - Lei $N^{o}$ 9.394, de 20 de dezembro. Brasília: Ministério da Educação.

Ministério da Educação. (2001a). Diretrizes Nacionais para a Educação Especial na Educação Básica - Parecer CNE/CEB 17/2001. Brasília: MEC/CNE/CEB.

Ministério da Educação. (2004). Direito à educação. Subsídios para a gestão dos sistemas educacionais: Orientações gerais e marcos legais. Brasília: Secretaria de Educação Especial do Ministério da Educação. 
Ministério da Educação. (2008). Política Nacional de Educação Especial na Perspectiva da Educação Inclusiva. Inclusão: Revista da Educação Especial, 4, 7-17.

Oliveira, E. P. L. (2007). Alunos sobredotados: A aceleração escolar como resposta educativa (Tese de doutorado). Universidade do Minho, Braga, Portugal.

Pérez, S. G. P. B. (2009). Ser ou não ser, eis a questão: $O$ processo de construção da identidade na pessoa com altas habilidades/superdotação adulta (Tese de doutorado). Pontifícia Universidade Católica do Rio Grande do Sul, Porto Alegre.

Renzulli, J. S. (1998). A rising tide lifts all ships. Phi Delta Kappan, 80, 104-112.

Renzulli, J. S. (2001). Enriching curriculum for all students. Arlington Heights, IL: SkyLight.

Roeper, A. (1982). How the gifted cope with their emotions. Roeper Review, 5, 21-24.

Rogers, K. B. (2004). The academic effects of acceleration. In N. Colangelo, S. G. Assouline, \& M. U. M. Gross (Eds.), A nation deceived: How schools hold back America's brightest students (Vol. II, pp. 47-57). Iowa City, IA: The Connie Belin \& Jacqueline N. Blank International Center for Gifted and Talented Development.

Rogers, K. B. (2007). Lessons learned about educating the gifted and talented: A synthesis of the research on educational practice. Gifted Child Quarterly, 51, 382-396.
Schiever, S. \& Maker, C. J. (1997). Enrichment and acceleration: An overview and new directions. In N. Colangelo \& G. Davis (Eds.), Handbook of gifted education (pp. 113-125). Boston, MA: Allyn and Bacon.

Shavinina, L. V. (Ed.). (2009). International handbook on giftedness. New York: Springer.

Silverman, L. K. (2002). Asynchronous development. In M. Neihart, S. M. Reis, N. M. Robinson, \& S. M. Moon (Eds.), The social and emotional development of gifted children. What do we know? (pp. 31-37). Washington, DC: Prufrock Press.

Steenbergen-Hu, S. \& Moon, S. (2011). The effects of acceleration on high-ability learners: A meta-analysis. Gifted Child Quarterly, 55, 39-53.

Terrassier, J. C. (1979). Gifted children and psychopathology. The syndrome of dyssinchrony. In J. J. Gallagher (Ed.), Gifted children: Reaching their potential (pp. 434440). Jerusalem: Kollek \& Son. 